\title{
Dysgerminoma - A Case Presentation
}

\begin{abstract}
ANETA TOMESCU1,2, LILIANA MOCANU33, DRAGOS BREZEANU2, GABRIELA STANCIU4*, RODICA SIRBU5, CEZAR TOMESCU1,2* ${ }^{1}$ Ovidius University of Constanta, Faculty of Medicine, 124 Mamaia Blvd., 900527, Constanta, Romania

${ }^{2}$ County Clinical Emergency Hospital Sf. Apostol Andrei, Second Department of Obstetrics and Gynecology, 145 Tomis Blvd., 900591, Constanta, Romania

${ }^{3}$ County Clinical Emergency Hospital Sf. Apostol Andrei, Anatomy and Pathology Department, 145 Tomis Blvd., 900591, Constanta, Romania

${ }^{4}$ Ovidius University of Constanta, Department of Chemistry and Chemical Engineering, 124 Mamaia Blvd., 900527, Constanta, Romania

${ }^{5}$ Ovidius University of Constanta, Faculty of Pharmacy, 124 Mamaia Blvd., 900527, Constanta, Romania

Dysgerminomas are a type of ovarian tumour which are developed from the germinal tissue and have a frequency of approximately $2 \%$ of all ovarian cancers. We report a case of a 40 years old female, which was admitted with abdominal pain and pollakiuria installed approximately 2 months ago. The particularity of the case lies in the late onset of the disease, compared to epidemiologic data, as well as in the immunohistochemical reactions, especially the negative PLAP reaction and positive CD30 reaction.
\end{abstract}

Keywords: Ovarian Tumour, Dysgerminoma, Immunohistochemistry

From the intrauterine life, the ovary is made up of three histological types of tissue: epithelium, germinal tissue, and sex cords. The three major ovarian tumours are represented by epithelial tumours, which are the most frequent ( $90-95 \%)$, the other $5-10 \%$ being represented by tumours of the sex cords and, less often, by germ cell tumours [1].

The most common germ cell tumour is the dysgerminoma, which has a frequency of approximately $2 \%$ of all ovarian cancers, with an incidence peak in adolescents and young adults [2,3].

\section{Experimental part}

40-year-old patient NM presented to the County Clinical Emergency Hospital of Constanta on 09.09.2014 at 16:47, complaining of pelvi-abdominal pain and pollakiuria for about two months. Following medical history and clinical examination, the decision to admit the patient on the Obstetrics-Gynecology department II with the diagnosis of pelvi-abdominal mass was made.

\section{Clinical examination}

From the patient's medical history we note that she is a heavy smoker and that she had one natural delivery and four elective curettages.

Upon abdominal palpation, a mass of approximately $20 / 20 \mathrm{~cm}$ located in the rightiliac fossa and the subumbilical region, which is painful with palpation and mobilization was detected. The hypogastrium and the left iliac fossa are normal. The mass is also detectable through digital vaginal examination and speculum examination.

\section{Laboratory findings}

In what regards laboratory findings, the following is noted: normal complete blood count and urinalysis and modified cancer antigen 125 (CA 125): 100.4U/MI (reference range under $35 \mathrm{U} /<\mathrm{MI}$ ).

The ECG shows a right bundle branch block, for which a cardiology consult is requested, which recommends periodic cardiologic assessment and monitoring of vital functions, particularly blood pressure levels and heart rate. Thoracic X-ray does not show any pulmonary lesions.

\section{Transvaginal ultrasound}

Ultrasound shows a $20 / 20 \mathrm{~cm}$ septatedmass replacing the right ovary, with colour Doppler hypervascularization. The uterus has a $7 / 4 \mathrm{~cm}$ size, with a homogenous structure and $a$ thin endometrial line of approximately $8 \mathrm{~mm}$. The left ovary has $3 / 2$ size and a normal ultrasound appearance. There is no liquid within the posterior vaginal pouch, Douglas.

\section{Surgical intervention}

On 11.09.2014 an emergency surgical intervention for acute surgical abdomen is decided upon. Upon opening of the peritoneal cavity, a pearly white 20/18 cmtumour mass with a bosselated surface and an intact capsule, belonging to the right ovary and mimicking the aspect of a uterine fibroma can be observed. The right fallopian tube, of normal macroscopic appearance, lines the mass. The uterus and left ovary and fallopian tube have a normal macroscopic appearance. A right anexectomy is performed. During the intervention, the specimen is sent to extemporaneous examination, which could not be performed, due to the fact that hospital device was malfunctioning at that moment. The specimen was subjected to paraffin test.

\section{Postoperative evolution}

During hospitalization, the patient's postoperative was favourable under antibiotic, anticoagulant, painkillers, and prokinetic treatment. The patient was discharged on the fourth post-op day in good general condition, afebrile, soft, non-tender abdomen, clean surgical wound, normal micturition, present bowel movements and no vaginal bleeding.

\section{Histopathology examination \\ Gross examination}

The laboratory received a $1000 \mathrm{~g}$ right anexectomy specimen, composed of an ovary with a $16 / 13 / 8 \mathrm{~cm}$ size, with an external surface of bosselated aspect, white-pink 
in colour, presenting translucid areas. Cross-section: multinodular aspect with sizes varying between 0.5 and 5 $\mathrm{cm}$, white-greyish in colour, separated by thin white bands, with areas of gelatinous aspect, in which areas of necrosis can be detected.

Materials and method

The specimen was fixed in formalin $10 \%$ for $24 \mathrm{~h}$; cold ischemic time: $2 \mathrm{~h}$. Tissues sections were taken and processed in paraffin: automated processing (Diapath platform); 5 micron sections were performed and conventional colouring techniques using usual kits (haematoxylin and eosin, Diapath) and special kits (PAS, Merck, Alcian blue 2,5 ph Diapath). Subsequently, the case was examined from an immunohistochemical point of view.

\section{Microscopic}

Microscopic examination: tumoral right ovary with the disappearance of normal histological structure, which is replaced by a neoplastic proliferation of cuboidal cells with large nucleolated nuclei, vesicular or dark, opaque chromatin, abundant clear or eosinophilic/granular/ amphophilic cytoplasm, with variable disposition: solid, glandular, trabecular; the tumoral stroma is fibrous connective tissue with myxoid areas, containing an inflammatory plasmacytic and lymphohistiocytic infiltrate, with focal formation of lymphoid aggregates. Unicellular and ischemic necrosis is present. Neural and lymphovascular invasion not detectable. Rare atypical mitosis are present. The ovarian capsule presents with tumour invasion, but it is not surpassed. The fallopian tube is infiltrated with tumour cells.

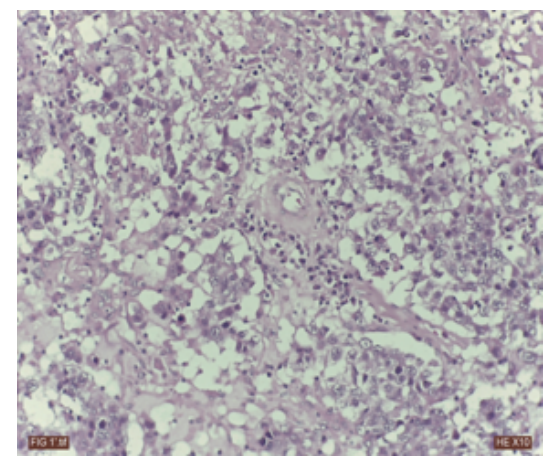

Fig. 1.HaematoxylinEosin10x magnification Tumour with cells represented by islets of large cells, with clear cytoplasm, in a stroma with an intense lymphoplasmacytic reaction

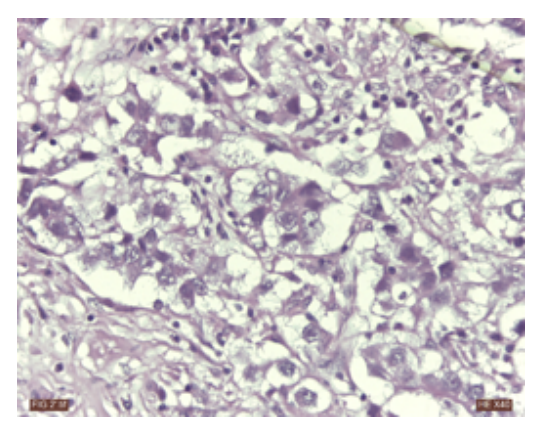

Fig. 2.HaematoxylinEosin 40x magnificationTumour with cells represented by islets of large cells, with clear cytoplasm, in a stroma with an intense lymphoplasmacytic reaction.

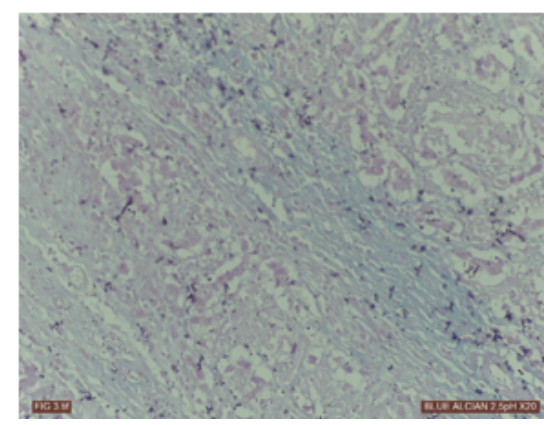

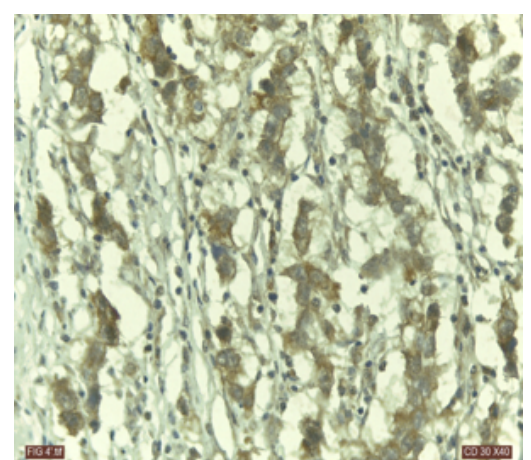

Fig. 4. CD3040 $\mathrm{x}$ magnification- Moderate positive perinuclear cytoplasm reaction. Internal positive control

in peritumoral

inflammatory cells.

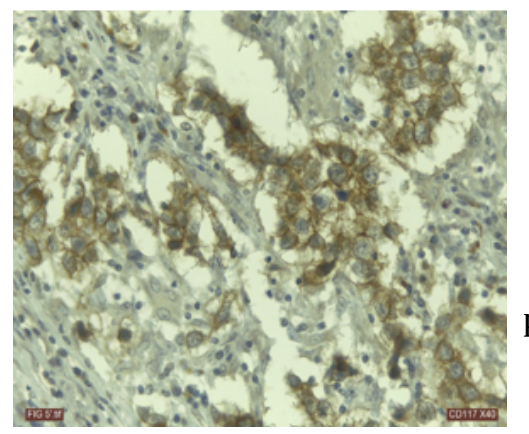

Fig. 5.CD11740x magnification.Moderate positive membrane complete reaction - focal incomplete.Positive internal control in peritumoral inflammatory cells

The preliminary conclusion of the histopathology examination was that of ovarian tumour, most probably a dysgerminoma.

Immunohistochemical examination was performed through the Polymer method, with a HRP detective system, on a semi-automated Biocare platform, with the following antibodies (Biocare):AE1/3 (clone AE1/3), Vimentin (clone V9), CK7 (clone OV-TL 12/30), CK20 (clone KS20.8), S100 (clone 15E2E2), EMA (clone E29), CEA (clone COL-1), KI67 (clone SP6), P53 (clone EP9), CD117 (clone EP10), CD30 (clone KI-1), CD99 (clone EP8), CALRETININ (N/A)), PLAP (clone SP15).

\section{Results and discussions}

The tumour was classified as a CD30 positive, PLAP negative dysgerminoma, with a positive aberrant reaction to CD 117, with a low mitotic index, p53, WILD type.

After receiving the histopathology result, the patient was taken into oncologic care with the diagnosis of ovarian neoplasm -embrional carcinoma G1 pt1NxMx stage and underwent four chemotherapy cycles with Bleomycin, Etoposide and Cisplatin. On 07.04.2015, she was admitted to the Medical Oncology Department for reevaluation. During hospitalization, the patient performed a toracoabdominal-pelvic CT scan, which a normal result. Discharge recommendation was to perform periodic consults with the treating gynaecologist. We must note that the patient refused radical surgical intervention or anexectomy of the controlateral ovary.

Currently, four years after the right anexectomy, the patient underwent another CT scan which shows no signs of relapse.

Dysgerminoma, the ovarian equivalent of the testicular seminoma, is a rare tumour, representing $1-2 \%$ of all malignant ovarian tumours [4]. It generally affects young women, most cases being diagnosed in the second and third decade of life and it has a very good prognosis (95\% 5 -year survival rate), even in advanced stages $[5,6]$.

Standard treatment is represented by surgical resection, followed by platinum salts chemotherapy and, in more advanced stages, adjuvant radiotherapy [7]. In our case, our patient refused resection of the controlateral ovary and is currently in perfect health four years after the initial diagnosis, with no signs of local or systemic relapse, even 
Table 1

LIST OF ANTIBODIES AND RESULTS

\begin{tabular}{|l|l|}
\hline Antibody & Result \\
\hline AE1/3 & + F $<10 \%$ \\
\hline VIM & - \\
\hline CK7 & - \\
\hline CK20 & - \\
\hline S100 & - \\
\hline EMA & - \\
\hline CEA & \\
\hline KI67 & - \\
\hline P53 & $+/++$ nc $5 \%$ \\
\hline CD117 & \\
\hline CD30 & + nc $50 \%$ \\
\hline CD99 & $++/+++$ cy + mb100\% \\
\hline Calretinin & - \\
\hline PLAP & - \\
\hline
\end{tabular}

+ weak positive; ++ moderatepositive; +++ intensepositive;

- negative; cy=cytoplasmatic; mb=membrane; nc=nuclear

though literature on the matter notes the recurrence of dysgerminoma on the remaining ovary in $5-10 \%$ of cases in the two years following surgical intervention. Other relapse sites are represented by the peritoneal cavity or mediastinal and paraaortic lymph nodes [8]. Out of all germ cell tumours, dysgerminoma has the best prognosis, due to the fact that it is chemotherapy sensitive even in advanced stages. Even in the case of relapse, the prognosis remains favourable, most patients showing a good response to chemotherapy, radiotherapy or the combined use of chemotherapy and surgery [7].

Our case was pretty typical in whatregardsconventional examination, but it did present unusual reactions at the immunohistochemical examination, represented by:

Weak ae1/3 positive reaction (which outlines the possibility for the tumour to differentiate on an epithelial line) $[9,10]$.

Negative PLAP reaction (registered in $50 \%$ of testicular seminoma cases) [10-12].
Unexpectedly wide positive CD30 reaction (rarely observed in testicular seminoma cases, and, according to literature data, only rarely in seminoma cells. However, this reaction is reported in almost all cases of embrional carcinoma and in almost $25 \%$ cases of yolk sac tumours [13-15] -this is in accordance with Suster et al.'s conclusion that the significance of CD30 positive reaction must not be restricted to embrional carcinoma, but that it can be extended to yolk sac tumours and seminomas and dysgerminomas, corresponding to the close histogenetic relationship that exists between these tumour types).

\section{Conclusions}

The particularity of the case lies in the late onset of the disease, compared to epidemiologic data, as well as in the immunohistochemical reactions, especially the negative PLAP reaction and positive CD30 reaction.

\section{References}

1.QUIRK J.T., NATARAJAN N., Ovarian cancer incidence in the United States 1992-1999,Gynecology,98, 2005, p. 519.

2.CHAD, M., MICHENER, M.D., Ovarian Dysgerminomas, ( 10 oct 2018) retrieved from http://emedicine.medscape.com/article/253701overview

3.HALE, J., Dysgerminoma in Children, Adolescent and Young Adults: A Report from the Malignant Germ Cell Tumour International Collaborative (MAGIC), $48^{\text {th }}$ Congress of the International Society of Paediatric Oncology, Conference Proceedings, 2016, P73-74

4.PECTASIDES, D., PECTASIDES, E., KASSANOS, D.,Cancer Treat Rev, 34,2008, p.427.

5.SIGISMONDI, C., SCOLLO, P., FERRANDINA, G., International J ournal of Gynecological Cancer,25(2), 2015, p. 203.

6.DEVIC, A., VASILJ EVIC, M., DEVIC, A., SORAK, M.,Serbian J ournal of Experimental and Clinical Research, 17(1), 2016, p. 67.

7.VICUS, D., BEINER, M., KLACHOOK, S., LE, L.,Gynecologic Oncology,117(1), 2010, p. 23.

8.KUMAR S, SHAH JP, BRYANT CS, IMUDIA AN, COTE ML, ALI-FEHMI R.,GynecolOncol., 110(2), 2008, p. 125.

9.COSSU-ROCCA, P., JONES, T.D., ROTH, L.M., EBLE J.N., ZHENG, W., KARIM, F.W., CHENG, L.,Hum Pathol., 37(8), 2006, p.1015.

10.KASPAR, H.,CRUM, C., Archives of Pathology \& Laboratory Medicine,139(1), 2015.

11.WICK, M.,Immunohistochemical Approaches To The Diagnosis Of Undifferentiated Malignant Tumors, Division of Surgical Pathology \& Cytopathology, University of Virginia Health System, Charlottesville, Virginia, USA, 2008

12.SUSTER, S., MORAN, C. A., DOMINGUEZ-MALAGON, H., QUEVEDOBLANCO, P.,Hum. Pathol., 29,1998, p. 737.

13.CHEVILLE, J. C., RAO, S., ICZKOWSHI, K. A., LOHSE, C. M., PANKRATZ, V. S.,Am. J. Clin. Pathol.,113(32),2000, p. 583.

14.DABBS, D., Diagnostic Immunohistochemistry: Theranostic and Genomic Applications. $4^{\text {th }}$ edition, Elsevier, p. 690:696

15.WEIDNER, N., COTE, R., SUSTER, S., WEISS, L., Modern Surgical PathologyElsevier Health Sciences.2009. $2^{\text {nd }}$ edition, p. 1387

Manuscript received: 28.10 .2018 